\title{
Methanol Extraction of Microbial Pigments For Polyester Fabric
}

\author{
"R.Priyanka, ${ }^{\# D r}$. M.Jayakumari \\ "Research Scholar, \#Assistant Professor, Department of Textiles and Apparel Design, Bharathiar \\ University, Coimbatore, Tamil Nadu, India. \\ "priyankarathakrishnan@gmail.com, "jayakumarim@yahoo.co.in
}

\begin{abstract}
Micrococcus Luteus is a bacterium that is Gram-positive. Bacteria with thicker cell walls are said to be grampositive bacteria, and it is said that thinner cell walls are gram-negative bacteria. In the natural flora of the mammalian body, micrococcus luteus is present in soil, dust, water and air. In the human mouth, mucosa, osopharynx, and upper airways, it is also present. In these two colonies, there are bright yellow pigments in the agar plate. Carotenoid containing a bright yellow color in the primary. M.luteus pigment with the highest variety of properties for anticarcinogenic and immune modulation. Anti-carcinogenic (an agent that destroys or prevents cancer cells).The yellow pigment has shown promising activity as antioxidant, antibacterial and UV-protective. Results that clearly indicate the potential application of these pigments after clinical trials as natural coloring agents and UV protection agents in food and pharmaceutical cosmetics in dustries. M.luteus has been shown to have activity. The strain was made of the coarse pigment. The dye absorbs Ultraviolet radiation and is used in cosmetics with sunscreen. It is a type of vitamin that is used in natural colors. In this study, the polyester fabric was chosen. In essence, polyester fabric is much less absorbent. But the color pigment was extracted using M.luteus methanol, which is showing very good promising color even for polyester fabrics.
\end{abstract}

Keywords: Micrococcus Luteus, medicinal use, methanol extraction, color pigments, polyester fabric,evaluation.

\section{INTRODUCTION}

\subsection{Micrococcus Luteus}

This is a bacterium that is Gram-positive. Gram-positive bacteria, though thinner cell walls are said to be gramnegative bacteria, are said to be bacteria with thicker cell walls. Micrococcus luteus is present in soil, dust, water and air in the natural flora of the mammalian body. It is also found in the mouth, mucosa, osopharynx, and upper airways of humans. It was first identified by Sir Alexander Fleming in 1928 before the discovery of penicillin. Negative coagulase (a protein enzyme produced by a number of micro-organisms) and bacitracin (a mixture produced by the organism of cyclic peptides). These two colonies make the agar plate with bright yellow pigments. Carotenoid producing bright yellow color in the primary. Micrococcus Luteus found an oligotrophic lake at Lake George, New York. It can exist for long periods of time in an oligotrophic environment.

Micrococcus is generally harmless, but there have been rare cases of micrococcus infections in people with compromised immune systems, as is the case with HIV patients. Micrococcus luteus rarely causes illness or body disorders, those known to be caused by m.luteus skin infections, or compromised immune systems such as patients with HIV. Bacterial infections are rare and the bacterium is a natural part of the bacterial flora of the body.

1.2.Medicinal Uses

In 2013, Norwegian researchers found that Micrococcus luteus strain synthesizes a pigment that absorbs light wave lengths from 350 to 475 nanometres. Exposure to these ultraviolet light wavelengths has been associated with an increased incidence of skin cancer, scientists believe that this pigment can be used to produce a sunscreen that can protect against ultraviolet light. M.luteus pigment has antibacterial activity against Staphylococcus sp, klebsiellasp, wound-isolated Pseudomonassp(KF532949).

M.luteus can function against bacteria that are gram negative and positive. Microbial dyes are attracted more attention. It has several benefits such as cheaper manufacturing, faster production, higher yields, raw material performance, lack of multiple variations. Thanks to biodegradability and greater environmental protection, bacterial pigments offer promising prospects for various applications in industries such as food, pharmaceuticals, cosmetics, textiles, etc. Anti-carcinogenic (the agent which 
destroys or stops cancer cells) This yellow pigment has shown promising Ultraviolet, antioxidant and antibacterial activity. The results clearly show the potential for these pigments to be used in the food and pharmaceutical industries as natural coloring agents as well as UV protection agents in cosmetics following clinical evaluations. The strain was made of the crude pigment. Pigment used in sunscreen makeup to remove UV radiation. It is a source of vitamin that is used in natural colours.

\subsection{Polyester Fabric}

Polyester is a synthetic fiber produced by the chemical action of alcohol acids from carbon, oil, water and air. A mixture of molecules in this reaction makes a large product with a structural repeat that maintains its form, hard to stain, throughout its length. For home furnishings, blankets, sheets, bed spreads, curtains, mattress ticking and table clothes, polyester and polyester mixtures are also used to enhance absorption and reduce static electricity polyesters. Also used in pillows, comforters, bedspreads, quilted sheets and other houses, winter jackets, etc.

\section{METHODOLOGY}

\subsection{Extraction of microbial pigments from bacteria}

\subsubsection{Materials Required For Finishing}

Fabric

Methanol Pigment

M:L:R

Drying Temp.

Time

Curing Temp

$\begin{array}{ll}- & \text { Polyester } \\ - & 100 \mathrm{ml} \\ - & 1: 5 \\ - & 60^{\circ} \mathrm{C}-70^{\circ} \mathrm{C} \\ - & 30 \text { minutes } \\ - & 60^{\circ} \mathrm{C}-70^{\circ} \mathrm{C}\end{array}$

\subsection{Isolation and Identification of pigment producing bacteria}

Soil suspensions are processed using sterile distilled water from the soil samples obtained. The loop was streaked on sterile nutrient agar plates full of soil suspension and the plates were incubated for 24 hours at $37^{\circ} \mathrm{C}$. Only the pigmented bacterial colonies have been selected and subcultivated for further analysis on the nutrient agar plates.

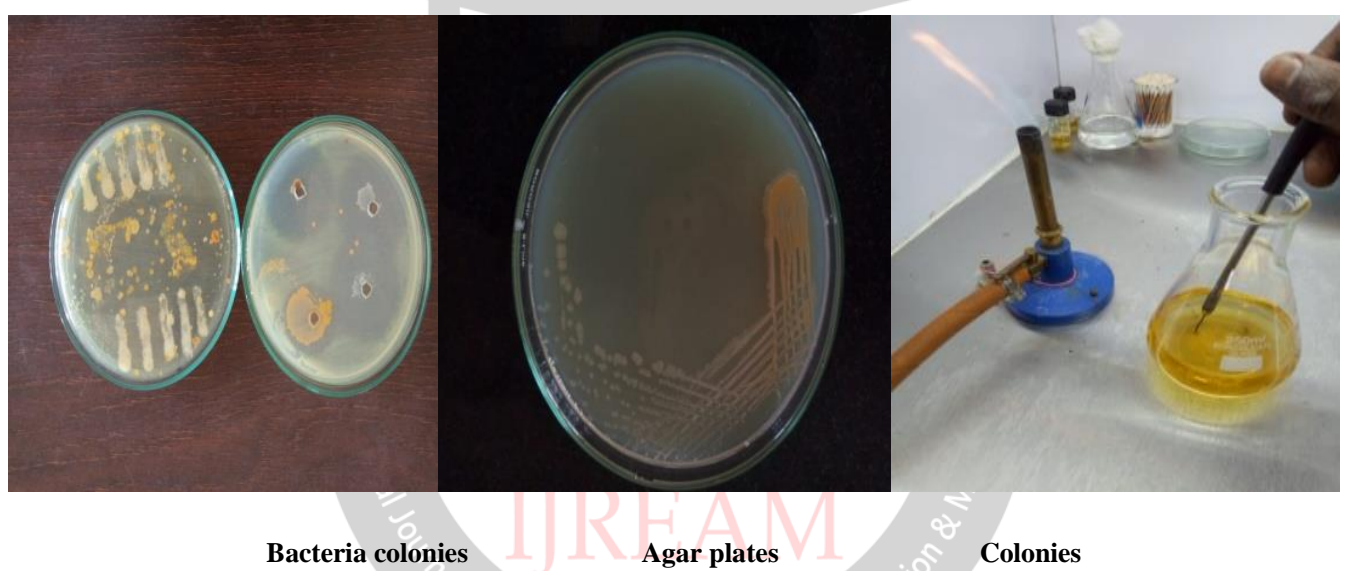

\subsection{Extraction of pigments}

Extracting the pigments using the oil fluid extraction method. The plants are inoculated in $100 \mathrm{ml}$ flasks of sterile Nutrient Broth. Two sets have been prepared: one in the $37^{\circ} \mathrm{C}$ static incubator and one in the $37^{\circ} \mathrm{C}$ temperature setting of the $90 \mathrm{rpm}$ rotary shaker. The pigment was extracted using cold centrifuge at the end of 7 days of incubation, with conditions set at $6,000 \mathrm{rpm} / 12 \mathrm{C} / 15$ minutes. The supernatant was extracted and the pellet was discarded mixed with methanol. The pigmented supernatants were further separated by the use of the separating funnel. Separate the colored supernatant and funnel it through the filter paper Whatman No.1.

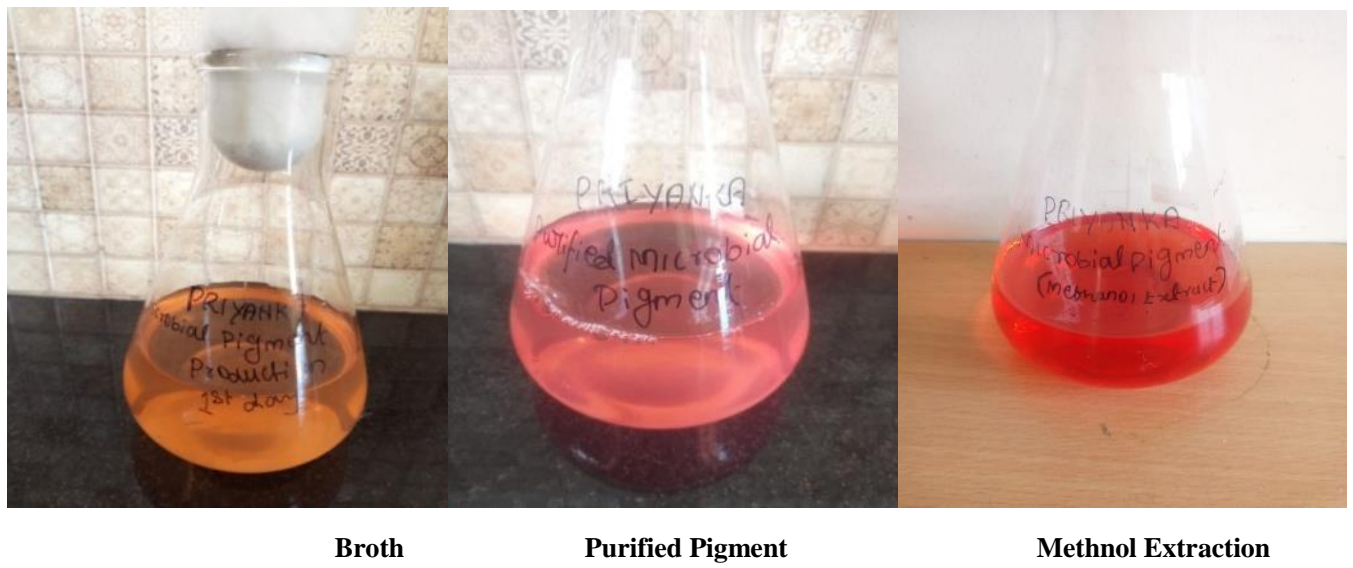




\section{RESULT}

4.1.Finishing of Extracted Pigments on Polyester Fabric Separately, the tissue samples are handled as a cross-linking agent using citric acid. The specimens of the fabric were treated separately with the pigments obtained as a crosslinking method using citric acid. The extracts are added to the fabric through the dip and dry process. The finished fabrics were taken and dried at $100-1200^{\circ} \mathrm{C}$ for $5 \mathrm{~min}$ and healed at $1800^{\circ} \mathrm{C}$ for $3 \mathrm{~min}$.

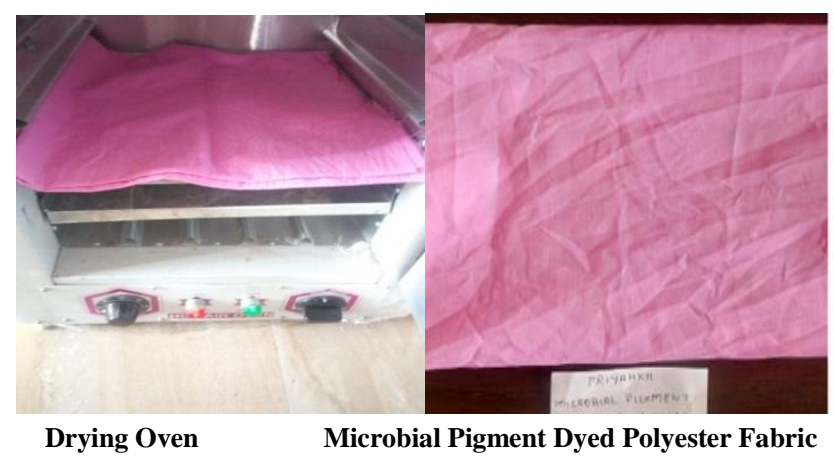

\section{CONCLUSION}

The color pigments extracted from M.luteus give a very good color even in polyester fabrics. The main advantage is that there are very few coloring pigments. This finished paint pigments made of polyester fabric also has special properties such as antibacterial, antifungal, antioxidant and carcinogenic activity. Dyeing properties are researched. The color speed test results in a very good result. More experiments can be done by adjusting the mordents to give different shades and colors.

\section{REFERENCES}

[1] Madigan M; Martinko J, eds. (2005). Brock Biology of Microorganisms (11th ed.). Prentice Hall. ISBN 978-013-144329-7

[2] Ohama, T; Muto, A; Osawa, S (1990). "Role of GCbiased mutation pressure on synonymous codon choice in Micrococcus luteus, a bacterium with a high genomic GC-content". Nucleic Acids Res. 18 (6): 1565-1569. Doi:10.1093/nar/18.6.1565. PMC 330526. PMID 2326195.

[3] Benecky M. J.; Frew J. E.; Scowen N; Jones P, Hoffman B. M (1993). "EPR and ENDOR detection of compound I from Micrococcus lysodeikticus catalase". Biochemistry. 32 (44): 11929-11933 [1]

[4] Tang, Jane. "Reclassification of ATCC 9341 from Microccusluteus to Kocuriarhizophila"(PDF). Retrieved 2 March 2011.

[5] SINTEF. "Super sunscreen from fjord bacteria." Science daily. Science daily, 6 August 2013.

[6] Smith, K.J.R.; Neafie, J. Yeager; Skelton, H.G (1999). "Micrococcus folliculitis in HIV-1 disease". British Journal of Dermatology. 141 (3): 558-561. Doi:10.1046/j.1365-2133.1999.03060.x - via British Association of Dermatologists.
[7] M, Madigan; Martinko, J (2005). Brock Biology of Microorganisms. Prentice Hall.

[8] Bacterial Identification. Clinical Microbiology and Infection 3. 1997. Pp. 53-56.

[9] Chinta SK and Rajesh Kumar singh. Processing Problems of Polyester And Its Remedies. International Journal of Engineering Research \& Technology 2012; $1(7): 1-19$.

[10] Kausar A. Review of fundamentals and applications of polyester nano composites filled with carbonaceous nano fillers. Journal of Plastic Film \& Sheeting 2019; 35(1):2244. 